5. Gall, R. J., and Greenspan, F. P., J. Am. Oil Chemists' Soc., $34,161(1957)$.

6. Greenspan, F. P., U. S. Patent $2,490,800$ (1949)

7. Greenspan, F. P., and Gall, R. J., Ind. Eng. Chem., 45, 2722 (1953).

8. Greenspan, F. P., Modern Plastics (March 1954).

9. Greenspan, F. P., and Gall, R. J., J. Am. Oil Chemists' Soc., 33, 391 (1956).

10. Greenspan. F. P., Gall, R. J., and Daly, M. O., presented at J. Am. Oil Chemists' Soc. Meeting, September 1956, Chicago.
11. Niederhauser, W. D., and Koroly, J. E., U. S. Patent 2,485,160

(1949)

12. Prileschajew, N., Ber., 42, 4811 (1909).

13. Swern, Daniel, Billen, G. N., Findley, T. W., and Scanlon, J. T. J. Am. Chem. Soc., 67, 1786 (1945)

14. Swern, Daniel, Chem. Rev, 45, 1 (1949).

15. Swern, Daniel, and Findley, T. W., U. S. Patent 2,569,502

(1951).

16. Terry, D. E., and wheeler, D. W., U. S. Patent 2,454,484 (1949).

[Received October 7,1957 ]

\title{
Biochemistry of the Sphingolipides. X. Phytoglycolipide, a Complex Phytosphingosine-Containing Lipide from Plant Seeds ${ }^{1,2}$
}

\author{
HERBERT E. CARTER, WALTER D. CELMER, ${ }^{3}$ DIMITRIS S. GALANOS, ${ }^{4}$ R. H. GIGG, ${ }^{4}$ WILLIAM \\ E. M. LANDS, ${ }^{5}$ JOHN H. LAW, ${ }^{6}$ KATHERINE L. MUELLER, TEISHI NAKAYAMA, ${ }^{4}$ \\ H. H. TOMIZAWA, ${ }^{\tau}$ and EVEL.YN WEBER, Division of Biochemistry, Noyes Laboratory \\ of Chemistry, University of Illinois, Urbana, Illinois
}

T HHE INOSTTOL-CONTAINING PHOSPHATIDES have been the subject of many investigations since Klenk and Sakai (20) first reported the presence of inositol in soybean lipides. Progress has been slow, partly because of the lack of satisfactory fractionation methods and of adequate criteria of purity; nevertheless some useful information has been obtained as to the nature and number of the inositolcontaining lipides of corn and soybean (11-13, 17, 18, 24-26, 32-35, 37). Folch (12, 13), Woolley (37), and others $(18,24,26)$ have obtained purified fractions of higher inositol content by solvent-fractionation procedures. These materials were reported to contain fatty acids, glycerol, inositol, and phosphate; certain preparations had, in addition, carbohydrate components and tartaric acid. The only nitrogenous substances detected were ethanolamine and serine, which is of some interest in the light of the results to be presented in this paper.

Dutton and co-workers $(32,33)$ and McGuire and Earle (22) have applied countercurrent distribution techniques to the lipides of corn, soybean, and flaxseed. By using a methanol-hexane system, two inositol-containing fractions were obtained, one moving with the hexane, the other remaining in the early methanol tubes. These results give no information as to the homogeneity of the fractions, and with this system emulsion problems limit the practical extension of the distribution process. However, in the course of these studies, galactose, arabinose, and mannose were identified by paper chromatography in various inositol lipide fractions (33).

The results of the countercurrent distribution and solvent-fractionation studies have established the occurrence of two types of inositides in plant lipides. The better characterized of these is phosphatidyl inositol, to which structure I has been assigned.

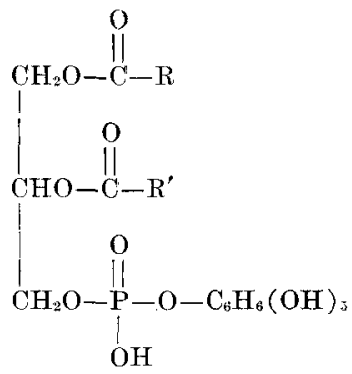

Phosphatidyl inositol has been isolated from several plant, sources [soybean (25), wheat germ (11), peas
(35) ], and a phosphatidyl inositol-like material with a phosphorus to inositol ratio of 1.8 has been obtained in a partially purified form from soybean (32).

The more complex carbohydrate-containing inositides have been less well-characterized. Folch (13) fractionated soybean phosphatides by a chloroformethanol technique and obtained a fraction which contained inositol, carbohydrate, glycerol, primary amine (unidentified) fatty acids, and phosphoric acid. Hawthorne and Chargaff (18), by a similar solvent-fractionation procedure, obtained an inositol lipide, which on hydrolysis gave an organic phosphate containing inositol, galactose, and arabinose. More recently Malkin and Poole (24) have purified similar fractions further and have tentatively assigned structure II

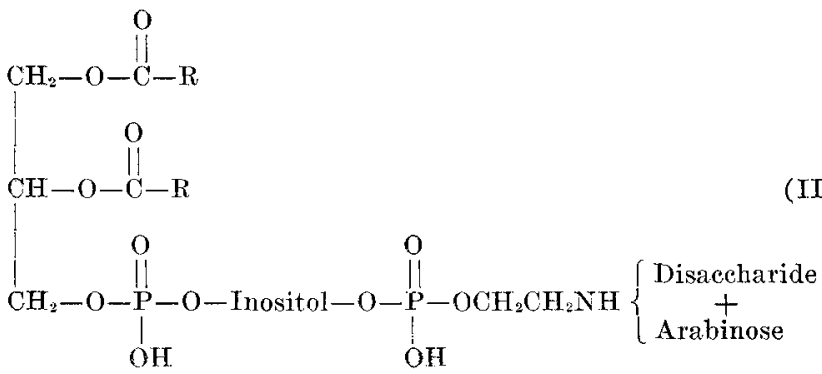

to the main constituent. It should be noted that none of these materials were established to be homogeneous.

Some years ago in our laboratories a procedure was devised for preparing a purified inositol lipide mixture $^{8}$ essentially devoid of lecithin, cephalin, sterols, and non-lipide contaminants (1). Countercurrent distribution studies on this material, using a methanol-

1 'The soybean phosphatide work was done under contract with the U. S. Department of Agriculture and was authorized by the Research and Marketing Act. The contract was supervised by Herbert $J$ Dutton and John C Cowan of the Northery Utilization Besearch and Develop ment Dirision of the A rricultural Reseaxch Service, Peoria, Ill. The corn phosphatide work was supported in part by research prant (B574-C2,3,4) from the National Institutes of Health, United States Public Health Service. Part of the material in this paper was taken from the theses submitted by Walter D. Celmer, William E. M. Lands, John $H$. Law, and H. H. Tomizawa to the Graduate College of the University of Illinois in partial fulfilment of the requirements for the

degree of Doctor of Philosophy in Chemistry. number IX in this series see reference (2).

${ }^{3}$ Present address, Chas. Pfizer and Sons, Brooklyn, N. Y.

Postdoctorate Research Associate, Department of Chemistry.

5 Present address, Department of Biological Chemistry, University of Michigan, Ann Arbor, Mich.

${ }^{\circ}$ Present address, Converse Memorial Laboratory, Harvard University, Cambridge, Mass.

Present address, University of Washington, School of Medicine,

8 In this paper the term inositol lipide (IL) will be used to designate the mixture of inositol-containing lipides which were obtained from rariety of plant seed phosphatides by this procedure. 
hexane system, gave results essentially identical with those of Scholfield and Dutton. Degradation studies on the crude corn $\mathrm{IL}^{8}$ led to the discovery of the presence of a long-chain basic constituent. This substance was shown to be identical with cerebrin base [isolated previously from yeasts and molds (5)], and its structure (III) was established by periodate oxida-

$$
\begin{gathered}
\mathrm{CH}_{3}\left(\mathrm{CH}_{2}\right)_{13} \mathrm{CH}-\mathrm{CH}-\mathrm{CH}-\mathrm{CH}_{2} \mathrm{OH} \\
\text { ! ! ! } \\
\text { OH } \mathrm{NH}_{2}
\end{gathered}
$$

tion (1). The base was designated as phytosphingosine because of its origin and close similarity in structure to sphingosine. Proštenik and Stanačev (29) have synthesized a mixture of the racemic forms of this substance.

The discovery of the presence of phytosphingosine in corn (and later soybean) phosphatides provided an additional analytical tool [McKibben-Taylor longchain base determination (23)], with which to follow fractionation procedures. It was decided therefore to make a further study of the countercurrent distribution as a method for the fractionation of inositol lipide mixtures. Investigation of several solvent systems provided one ( $n$-heptane, $n$-butanol, methanol, water) which gave satisfactory distribution of the components with less difficulty with emulsions. Using this system, $30-, 100$-, and 400-transfer distributions have been carried out on corn IL.

In the 100-transfer (single withdrawal) distribution three peaks were observed [tubes 6 (peak A), 24 (peak B), and 56 (peak C), respectively]. Peaks $A$ and $B$ overlapped, but peak $C$ moved almost with the heptane front (Figure 1).

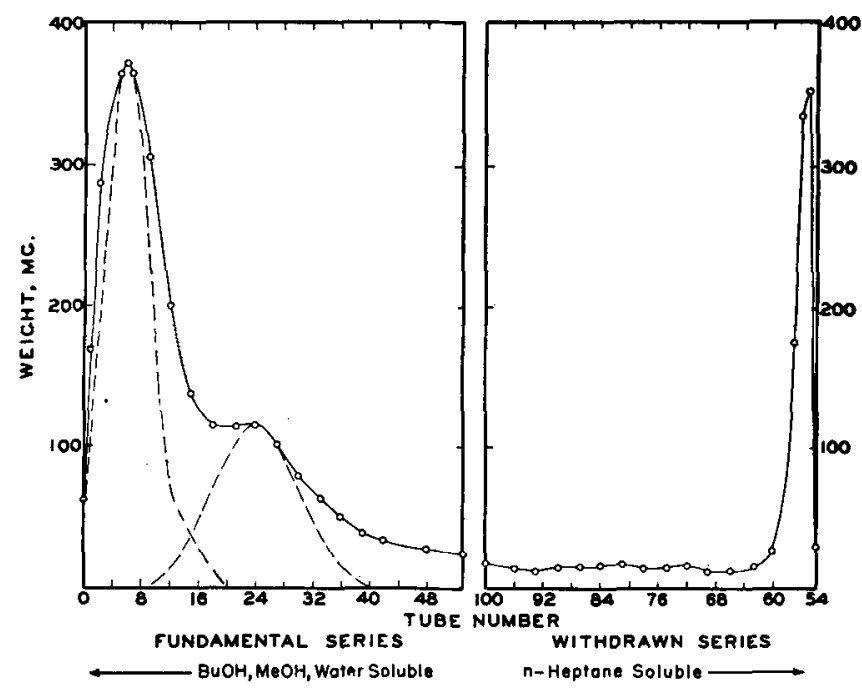

FIG. 1. 100-transfer countereurrent distribution of corn IT, in $n$-heptane, $n$-butanol, methanol, water system. o-o-o experimental. ..._ _ _ theoretical.

Through the courtesy of H. J. Dutton (Northern Regional Utilization Branch, U.S.D.A.), a 400-transfer (single withdrawal) separation was made with a 200-tube automatic apparatus. Unfortunately several fractions were lost (tubes 46-60). However the analytical data (Tables I and II) show a cleaner separation of peaks $A_{1}$ and $B_{1}$ and the partial resolution of $\mathrm{B}_{1}$ into three peaks $\left(\mathrm{B}_{1}, \mathrm{C}_{1}, \mathrm{D}_{1}\right)$. The main heptanesoluble fraction has been separated into two peaks $\left(\mathrm{E}_{1}, \mathrm{~F}_{1}\right)$. All fractions contained inositol, and all
TABLE I

Countercurrent Distribution of Corn Inositol Lipide*

\begin{tabular}{|c|c|c|c|c|c|c|}
\hline \multirow{2}{*}{ Fraction } & \multirow{2}{*}{$\begin{array}{l}\text { Tubes } \\
\text { com- } \\
\text { bined }\end{array}$} & \multirow{2}{*}{ Weight } & \multicolumn{2}{|c|}{ Nitrogen } & \multirow{2}{*}{$\begin{array}{l}\text { Phos. } \\
\text { phorus }\end{array}$} & \multirow{2}{*}{ Carb." } \\
\hline & & & Total & LCB b & & \\
\hline 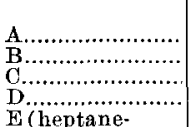 & $\begin{array}{r}0-11 \\
12-18 \\
19-30 \\
31-53\end{array}$ & $\begin{array}{l}g m . \\
1.55 \\
0.52 \\
0.62 \\
0.40\end{array}$ & $\begin{array}{l}\% \\
0.44 \\
0.76 \\
1.17 \\
1.18\end{array}$ & $\begin{array}{l}\% \\
0.15 \\
0.32 \\
0.45 \\
0.54\end{array}$ & $\begin{array}{l}\% \\
2.90 \\
2.92 \\
1.98 \\
1.41\end{array}$ & $\begin{array}{r}\% \\
\ldots .0 \\
5.0 \\
8.3 \\
12.7\end{array}$ \\
\hline $\begin{array}{r}\text { soluble) .......... } \\
\text { Corn IL................. }\end{array}$ & $\begin{array}{c}54-62 \\
\ldots . \\
\end{array}$ & $\begin{array}{r}0.57 \\
4.00 \\
\end{array}$ & $\begin{array}{l}1.05 \\
0.80\end{array}$ & $\begin{array}{l}0.24 \\
0.31\end{array}$ & $\begin{array}{l}5.35 \\
3.70 \\
\end{array}$ & $\begin{array}{l}5.5 \\
6.0\end{array}$ \\
\hline
\end{tabular}

" Four grams of corn inositol lipide dissolved in $80 \mathrm{ml}$. of uppe phase ( $n$-heptane- $n$-butanol-methanol-water system); solution introduced as upper phase of Tube 0 in 54-tube apparatus and subiected to 100-transfer single withdrawal distribution. All analytical data expressed as weight $\%$ of the lipide fraction analyzed.

b Long chain base nitrogen as determined by the McKibben-Taylor procedure (19); both sphingosine and phytosphingosine are determined by this method.

Carbohydrate values determined as galactose by the anthrone procedure (30) applied to the unhydrolyzed lipide fraction.

except $\mathrm{E}_{1}$ contained glycerol. Fraction $\mathrm{A}_{1}$ was carbohydrate-free and low in nitrogen. It appeared to contain mainly phosphatidyl inositol and, by the lead salt precipitation procedure of Scholfield and Dutton (32), yielded an essentially nitrogen-free inositol phosphatide.

Fractions $\mathrm{C}_{1}$ and $\mathrm{D}_{1}$ were rich in phytosphingosine which accounted for $30-50 \%$ of the total nitrogen. They contained in addition glycerol, inositol, and carbohydrate.

Fraction $\mathrm{E}_{1}$ (the major heptane peak) contained an unusual substance, high in phosphorus and ash. On acid hydrolysis it yielded inositol polyphosphate, fatty acids, a small amount of glycerol, and several ninhydrin-positive substances. Alkaline hydrolysis of Fraction $\mathbf{E}_{1}$ gave an insoluble product (salts of inositol polyphosphate?) with an ash content of 60 $65 \%$. Since Fraction $\mathrm{E}_{1}$ material oceurred in several of the phosphatides examined and was obtained consistently by procedures described later, it was decided to name it lipophytin. In our experience lipophytin is always present in inositol lipide preparations, the phosphorus content of which exceeds $4.0 \%$. Its presence in crude phosphatides and in the inositol lipide preparations complicates purification of the phytosphingolipides. Hence considerable effort was devoted to devising procedures for its removal other than the tedious countercurrent distribution method. It was discovered that lipophytin can be precipitated from chloroform (or hexane) solutions of inositol lipide by adding a limited amount of ethanol (not more than one volume). However the main bulk of the inositol lipide is precipitated when two volumes of ethanol are added. This procedure therefore is not sufficiently specific but can be used to remove the bulk of the lipophytin together with small amounts of other inositol-containing lipides. A somewhat cleaner separation was obtained by dissolving the inositol lipide in the upper (hexane-rich) phase of a hexane-butanol-

TABLE II

Countercurrent Distribution of Corn Inositol Ijipidea

\begin{tabular}{|c|c|c|c|c|c|c|}
\hline \multirow{2}{*}{ Fraction } & \multirow{2}{*}{$\begin{array}{l}\text { Tubes } \\
\text { combined }\end{array}$} & \multirow{2}{*}{ Weight } & \multicolumn{2}{|c|}{ Nitrogen } & \multirow{2}{*}{$\begin{array}{l}\text { Phos- } \\
\text { phorus }\end{array}$} & \multirow{2}{*}{ Carb. } \\
\hline & & & Total & LCB & & \\
\hline & & $g$ & $\%$ & $\%$ & $\%$ & $\%$ \\
\hline At... & $25-45$ & 2.40 & 0.37 & 0.11 & 3.95 & none \\
\hline$B_{1} \ldots$ & $80-95$ & $\begin{array}{l}.40 \\
1.50\end{array}$ & 0.43 & 0.16 & $\begin{array}{l}2.05 \\
2.95\end{array}$ & none \\
\hline $\mathrm{C}_{1}, \ldots \ldots \ldots \ldots \ldots \ldots \ldots \ldots$ & $115-140$ & 1.74 & 1.25 & 0.53 & 2.22 & 8.5 \\
\hline $\mathrm{D}_{1}$ & $150-175$ & 1.50 & 1.12 & 0.38 & 2.91 & 5.5 \\
\hline E1(heptane)......... & $205-235$ & 1.20 & 0.96 & 0.19 & 10.08 & 4.5 \\
\hline$F_{1}$ (heptane) .......... & $290-335$ & 0.61 & 0.30 & 0.10 & 2.90 & 10.8 \\
\hline Corn IL................. & .... & 16.00 & 0.80 & 0.31 & 3.70 & 6.0 \\
\hline
\end{tabular}

Sixteen grams of corn inositol lipide dissolved in $160 \mathrm{ml}$. of upper phase; solution distributed as upper phase of tubes $0-7$ in 200 -tube apparatus and subjected to 400 transfer single withdrawal distribution. Data recorded as in Table I. 
methanol water system and adding an equal volume of the lower phase. Lipophytin separated, and centrifugation of the lower phase at $-5^{\circ}$ gave a light $\tan$ solid (about 5-8\% yield) with a phosphorus content of 11-12\%. The purified inositol lipides obtained by this procedure generally had a phosphorus content of $3.7-3.8 \%$.

Although fractions $\mathrm{C}_{1}$ and $\mathrm{D}_{1}$ of the 400-transfer distribution were considerably enriched in longchain base, it was obvious that many more transfers would be necessary to obtain homogeneous samples of these components. In addition, this method limits the amount of material which can be obtained, and it seemed probable that large samples might be necessary for chemical studies. Therefore, before pursuing countercurrent distribution methods further, it was decided to attempt the purification of the phytosphingolipide fraction by other procedures.

Schmidt et al. (31) have employed mild alkaline saponification for the separation of sphingolipides from glycerolipides. Under the conditions employed, ester groups are hydrolyzed and glycerol-derived phosphatides are converted to fatty acid salts and other water-soluble products. Sphingomyelins and cerebrosides are stable under these conditions and can be separated readily from the hydrolysis mixture. In the hope of obtaining the phytosphingolipide fraction free of other phospholipides, corn IL was subjected to mild alkaline hydrolysis. The product was an amorphous insoluble precipitate, which could be freed of fatty acids by acetone extraction and further purified by precipitation from pyridine solution with ethanol. The same material could be obtained (in proportionately lower yields) from the original corn phosphatide. Similar products were subsequently obtained from soybean, flax, peanut, wheat, cottonseed, and sunflowerseed phosphatides. In view of the similarity in properties and constancy of chemical composition of these products the term phytoglycolipide has been applied to them. Typical data on the preparation and purification of phytoglycolipide from several sources are presented in Tables III, IV, and V. The purified phytoglycolipide samples were obtained as white amorphous powders, which were almost insoluble in the common organic solvents except in the basic ones, such as pyridine and morpholine. Phytoglycolipide dissolved slowly in aqueous alkali, giving a soapy solution from which the free acid could be precipitated by acidification to $\mathrm{pH} 1$. Addition of acetone to the aqueous suspension resulted in a precipitate which filtered more readily. Phytoglycolipide, obtained by precipitation from pyridine, was ashfree and gave a nitrogen to phosphorus ratio of about $2: 1$ and a total nitrogen to long-chain-base nitrogen of $2: 1$. [An uncharacterized material with similar nitrogen and phosphorus analyses and similar solubility properties has been prepared from soybean phosphatides by van Handel (34)]

TABLE III

Analyses of Tnositol Lipides and Commercial Phosphatides

\begin{tabular}{|c|c|c|c|}
\hline Starting material & Nitrogen & $\begin{array}{c}\text { LCB } \\
\text { nitrogen a }\end{array}$ & $\begin{array}{l}\text { Phos- } \\
\text { phorus }\end{array}$ \\
\hline & $\%$ & $\%$ & $\%$ \\
\hline Corn IL....... & 0.94 & 0.32 & 4.83 \\
\hline Flaxseed IL............................................. & 0.92 & 0.41 & 3.46 \\
\hline Soybean lecithin............................... & 0.99 & 0.056 & 2.79 \\
\hline 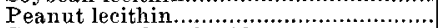 & 3.21 & 0.051 & 1.27 \\
\hline Cottonseed phosphatides...................... & 1.32 & 0.044 & 3.89 \\
\hline Sunfiowerseed phosphatides.................. & 1.03 & 0.129 & 2.93 \\
\hline Wheat germ phosphatides...................... & 1.46 & 0.089 & 3.17 \\
\hline
\end{tabular}

a Long-chain base nitrogen.
TABLE IV

Crude Phytoglycolipides from Thannhauser-Schmidt Hydrolyses

\begin{tabular}{|c|c|c|c|c|}
\hline Starting material & Yield & $\begin{array}{c}\text { Nitro- } \\
\text { gen }\end{array}$ & $\underset{\text { nitrogen }}{\text { LCB }}$ & $\begin{array}{l}\text { Phos- } \\
\text { phorus }\end{array}$ \\
\hline & $\%$ & $\%$ & $\%$ & $\%$ \\
\hline Corn $I I_{L} \ldots . .$. & 37.0 & 1.53 & 0.75 & 2.66 \\
\hline Flaxseed IL......... & 38.0 & 1.57 & 0.80 & 2.06 \\
\hline Soybean lecithin.. & 7.2 & 0.62 & 0.37 & 0.49 \\
\hline 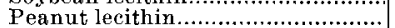 & 11.0 & 0.82 & 0.40 & 1.10 \\
\hline Cottonseed phosphatides.................. & 3.8 & $0.8 \overline{3}$ & 0.36 & 1.09 \\
\hline Sunflowerseed phosphatides............ & 7.5 & & 0.44 & \\
\hline Wheat germ phosphatides............... & 16.5 & 0.95 & 0.25 & 1.03 \\
\hline
\end{tabular}

As indicated earlier, the preparation of phytoglycolipide is complicated by the presence of lipophytin, which forms the high phosphorus, water-insoluble material on alkaline hydrolysis. This difficulty can be avoided by removal of lipophytin prior to the hydrolysis step. Or, alternatively, the degradation product, which is relatively insoluble in pyridine, can be removed in the purification of the phytoglycolipides. However mechanical difficulties complicate this step, and some phytoglycolipide is lost.

Since the preparation of inositol lipide is a tedious process, a study was made of the preparation of phytoglycolipide directly from commercial phosphatides. Commercial soybean lecithin from several sources was employed in these studies. Mild alkaline saponification yielded a crude phytosphingolipide fraction containing sterol glucoside, in addition to the "high-phosphorus" impurity. The former can be removed by extraction with chloroform-ethanol (1:1) and the latter in the usual way. By this procedure it is possible to prepare large quantities of phytoglycolipide directly from crude soybean and corn phosphatides with the minimum of operations.

Composition of Phytoglycolipide. The purified phytoglycolipides gave strong positive Molisch and anthrone tests. The Scherrer inositol test was positive, and a weak ninhydrin test was obtained with an anhydrous pyridine reagent (not in $50 \%$ aqueous pyridine). Since long-chain base nitrogen accounted for about half of the total nitrogen, it was presumed that an ethanolamine moiety was responsible for the ninhydrin test. The purified lipide gave a negative Lieberman-Burchard sterol test.

The infrared spectra of various samples of phytoglycolipide were identical and showed the expected peaks, including strong amide bands at 1,530 and $1,640 \mathrm{~cm}^{-1}$. In addition, a broad medium strength peak at $1,720 \mathrm{~cm}^{-1}$ was present. This could result from a carboxyl or a lactone group and was particularly interesting in view of the reported presence of tartaric acid in soybean lipositol (37).

Further information (both qualitative and quantitative) concerning the composition of phytoglycolipide was obtained by various hydrolytic degradations. Previous studies $(16,17,33)$ had shown the presence of soybean inositol lipides of galactose, arabinose, and mannose, and the first two had been detected in corn (33) and peanut (17) phosphatides. A careful chromatographic study was made of the

\begin{tabular}{|c|c|c|c|c|c|}
\hline \multicolumn{6}{|c|}{$\begin{array}{c}\text { TABLE V } \\
\text { Properties of Purified Phytoglycolipides }\end{array}$} \\
\hline \multirow[t]{2}{*}{ Source } & $\begin{array}{l}\text { Nitro- } \\
\text { gen }\end{array}$ & $\begin{array}{c}\text { LOB } \\
\text { Nitro- } \\
\text { gen }\end{array}$ & $\begin{array}{l}\text { Phos- } \\
\text { phorus }\end{array}$ & $\begin{array}{c}\text { An- } \\
\text { throne }\end{array}$ & $\begin{array}{l}{[a\rceil_{\mathbf{D}}^{25}} \\
\text { (pyri- } \\
\text { dine) }\end{array}$ \\
\hline & $\%$ & $\%$ & $\%$ & $\%$ & degrees \\
\hline Corn $\ldots \ldots \ldots \ldots \ldots \ldots \ldots \ldots$ & 1.88 & 0.73 & 1.93 & 20 & +50 \\
\hline Flaxseed............................... & 1.68 & 0.83 & 1.84 & 15 & +47.3 \\
\hline Soybean ......................... & 1.66 & 0.79 & 2.07 & 20 & +53 \\
\hline 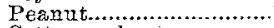 & 1.73 & 0.64 & 1.93 & & +50.6 \\
\hline Cottonseed............ & 1.66 & 0.80 & 2.01 & 15 & +47 \\
\hline Sunflowerseed.... & 1.60 & 0.60 & 1.66 & 20 & +51 \\
\hline
\end{tabular}


water-soluble material produced by mild acid hydrolysis of various phytoglycolipide samples, using lutidine-water and butanol-acetic acid-water systems. Galactose, arabinose, and mannose were found in hydrolysates of all the samples tested. Furthermore in a rough semi-quantitative comparison there appeared to be approximately equimolar concentrations of the three sugars. The presence of mannose was confirmed by preparation of the phenylhydrazone. A preparative scale isolation and separation of the three sugars is now under way in order to characterize each by physical properties and preparation of derivatives.

It is interesting to note that in the course of these studies, involving many individual experiments, no disaccharide was ever detected. Although far from conclusive, this observation might suggest that the three sugars are not attached to each other. Other explanations are of course possible. This relationship will make elucidation of structure of the intact lipide more difficult.

Inositol and inositol monophosphate have been shown to occur in soybean phosphatide by Klenk and Sakai (20) and in soybean IL in our laboratories. These substances could have arisen however from the phosphatidyl inositol compounds. Therefore it was necessary to carry out similar studies on phytoglycolipide. (It should be noted that phosphatidyl inositol is cleaved by mild alkaline hydrolysis whereas no inositol or inositol phosphate is liberated from phytoglycolipide under these conditions.) Paper chromatography of a 6 -hour, $6 \mathrm{~N} \mathrm{HCl}$ hydrolysate of phytoglycolipide established the presence of inositol, but no inositol phosphate was detected. With a 1-hour hydrolysis, inositol monophosphate did appear and has heen characterized by paper chromatography. It should be noted that no other sugar phosphate has been detected in acid or alkaline hydrolysates. This observation is of importance in considering possible structures for phytoglycolipide.

Three nitrogenous bases, ethanolamine (37), serine (19), and phytosphingosine (1), have been reported in inositol lipides from plant sources. Since phytoglycolipide has a nitrogen to phosphorus ratio of $2: 1$ and half of the nitrogen in long-chain base nitrogen, it was assumed that ethanolamine and/or serine contributed the remaining nitrogen. Chromatography of acid hydrolysates of phytoglycolipide gave a number of ninhydrin-positive spots. Two of these corresponded approximately to ethanolamine and serine (or perhaps ethanolamine phosphates). Isolation of the basic substance (s) by ion exchange chromatography gave an amine hydrochloride, the infrared spectrum of which showed polyhydroxy absorption, and was indeed essentially identical to the spectrum of glucosamine hydrochloride. A large-scale isolation gave a crystalline hexosamine hydrochloride in almost $10 \%$ weight yield. Infrared spectrum, X-ray diffraction pattern, optical activity, and chromatographic behavior of this material were identical with those of D-glucosamine hydrochloride. D-Glucosamine alone when subjected to treatment with $6 \mathrm{~N} \mathrm{HCl}$ gives several ninhydrinpositive spots, one of which resembles that of ethanolamine hydrochloride. It is essential to use some caution in interpreting paper chromatographic results on strong acid hydrolysates of glycolipides. We believe that the ninhydrin-positive spots observed in hydrolysates of phytoglycolipide can all be accounted for by the presence of phytosphingosine and glucos- amine although the presence of minor amounts of ethanolamine cannot be rigorously excluded. AIthough D-glucosamine has been observed in several animal glycolipides (for review see 3), it has not been reported previously as a constituent of plant lipides.

The presence of phytosphingosine in soybean II. was established by Carter et al. (1), and in the course of this work the long-chain base determination of MeKibben and Taylor (23) was used to follow the purification of phytoglycolipide. The analytical data show that $70-90 \%$ of the phytosphingosine of inositol lipide fractions is recovered as phytoglycolipide. The recovery from soybean phosphatide is considerably lower, suggesting that other types of phytosphingolipides may be present in the commercial phosphatide. This point is under investigation. It is interesting that, whereas corn phosphatide yields phytosphingosine (and its anhydro derivative) on acid hydrolysis, soybean IL yields in addition an unsaturated derivative of phytosphingosine, the structure of which is under study. The phytoglycolipides obtained from the two sources show a similar behavior.

The fatty acid constituents of phytoglycolipide were also characterized. Soybean phytoglycolipide fatty acids consisted of about $5 \%$ cerebronic acid ( $a$-hydroxytetracosanoic acid) and $95 \%$ of a mixture of stearic and palmitic acids; corn phytoglycolipide gave a mixture of $\mathrm{C}_{24}$ and $\mathrm{C}_{26}$-hydroxy acids $(65 \%)$, lignoceric acid $(11 \%)$, and a stearic-palmitic acid mixture $(24 \%)$. It is interesting to note that animal sphingolipides also contain high proportions of $\mathrm{C}_{24}$ acids (cerebronic, lignoceric, nervonic).

The established components of phytoglycolipide (fatty acid, phytosphingosine, inositol, glucosamine, galactose, arabinose, mannose, phosphate) accounted for most, but not all, of the properties of phytoglycolipide. Although analytical data on substances of such high molecular weight are not highly definitive, nonetheless the nitrogen and phosphorus values were consistently lower than would be expected from substances containing these moieties, joined by glycosidic, phosphate diester, and amide bonds. The analytical data clearly indicated the presence of a highly oxygenated constituent of at least four carbons. Furthermore the carboxyl absorption in the infrared spectrum remained to be allocated.

Since tartaric acid had been reported as a constituent of soybean lipositol, several attempts were made to isolate tartaric acid or a derivative thereof from phytoglycolipide. These attempts were uniformly unsuccessful. In reviewing various types of hexosamine derivatives known to occur in nature, hyalobiuronic acid (36) and chondrosine (8) came under consideration. The presence of a hexuronic acid moiety in phytoglycolipide would satisfy the analytical data and provide a carboxyl group. The failure to detect the unknown substance on papergrams would be explained by the known instability of the hexuronic acids to strong acids. Application of the Dische carbazole reaction (10) indicated clearly the correctness of this surmise, and degradation studies, to be reported in a subsequent paper, established the presence of a hexuronic acid-glucosamine moiety in phytoglycolipide.

All of the properties of phytoglycolipides can now be accounted for on the basis of the known constituents. The uniform presence of these substances and the similar physical properties of phytoglycolipide 
samples from several different sources strongly supports the view that phytoglycolipide as prepared is a relatively homogeneous new type of sphingolipide derivative which oceurs generally in plant seeds.

Further studies on this interesting substance are now in progress. One of the immediate problems is whether phytoglycolipide occurs as such or as a more complicated derivative in the original phosphatides. The solubility properties of phytoglycolipide are so markedly different from those of crude inositol lipide that it seems hardly possible to account for the discrepancies on the basis of mutual solubility effects. It seems more probable that a less polar moiety was cleaved from phytoglycolipide during the alkaline hydrolysis. The presence of glycerol in the phytosphingolipide fractions of the countercurrent distribution suggests that a phosphatidyl moiety may be attached to phytoglycolipide, and the analytical data of fractions $\mathrm{C}$ and $\mathrm{D}$ are consistent with this hypothesis. The final answer to this question will require the isolation of the intact lipide by non-hydrolytic methods, and to this end the countercurrent distribution studies are now being renewed.

\section{Experimental}

Analytical Methods. Nitrogen was determined by the micro-Kjeldahl method and phosphorus by a slight modification of the procedure of Harris and Pranjivar (15). "Long-chain base" nitrogen was determined by the procedure of MeKibben and Taylor (23). Paper chromatographic procedures are referred to in the individual sections.

Preparation of Corn. IL. A sample of Vodol corn phosphatide (400 g.) was placed in a 12-liter flask, and four liters of glacial acetic acid were added. The mixture was stirred for $1 \mathrm{hr}$. The solution was filtered on a Büchner funnel. The insoluble material was resuspended in two liters of glacial acetic acid and again filtered. The moist insoluble material (weight 180 g.) was divided between two 500-ml. centrifuge bottles; $45 \mathrm{ml}$. of water and $80 \mathrm{ml}$. of benzene were added to each bottle. The bottles were tightly corked and shaken manually for $5 \mathrm{~min}$. until no large particles settled to the bottom. Then the bottles were centrifuged, and the clear upper phase was siphoned off. (When the upper phase contained some suspended material even after prolonged centrifugation, the upper phase was allowed to settle in the cold over-night). The aqueous layer was re-extracted with $30 \mathrm{ml}$. of benzene for each bottle, and the benzene layer was separated by centrifugation. The combined benzene layers were lyophilized, giving 53 g. of brownish powder. This was extracted with $530 \mathrm{ml}$. of chloroform-ethanol mixture $(1: 2 \mathrm{v} / \mathrm{v})$ with stirring for $1 \mathrm{hr}$. The mixture was filtered, and the insoluble material was separated by filtration and washed with a small amount of chloroformethanol. The moist insoluble material was dissolved in a minimum amount of benzene and lyophilized. The inositol lipide thus obtained weighed $46 \mathrm{~g}$.

Preparation of Soybean Inositol Lipide. A 400-g. sample of Sta-sol (soybean lecithin) was added to four liters of glacial acetic acid with continuous stirring in a 12-liter flask, and the mixture was stirred for $1 \mathrm{hr}$. The glacial acetic acid became dark brown in color. After the stirring was stopped, a dark brown, gummy solid settled to the bottom. The acetic acid was separated by decantation, the gum was washed with $400 \mathrm{ml}$. of glacial acetic acid, which was also decanted. The moist gum (weight $115 \mathrm{~g}$.) was dissolved in $500 \mathrm{ml}$. of benzene and divided evenly in two $500-\mathrm{ml}$. centrifuge bottles; $25 \mathrm{ml}$. of water were added to each bottle. The bottles were shaken and centrifuged. The clear benzene layer was siphoned off and lyophilized. The lyophilizate weighed $53 \mathrm{~g}$. The product was next treated with 500 $\mathrm{ml}$. of chloroform-ethanol $(1: 2 \mathrm{v} / \mathrm{v})$. The mixture was stirred for $1 \mathrm{hr}$. and centrifuged. The supernatant was decanted, and the remaining solid was dissolved in $250 \mathrm{ml}$. of benzene and lyophilized. The crude inositol lipide was obtained in a yield of $35 \mathrm{~g}$.

Countercurrent Distribution Studies. These studies were made in the Craig type of apparatus. The 100-transfer distribution was performed in a 53-tube machine (tube capacity, $80 \mathrm{ml}$. of each phase) by the single withdrawal technique (17). The 400-transfer distribution was performed in a fully automatic 200tube apparatus (tube capacity $40 \mathrm{ml}$. of each phase), again with the single withdrawal technique. In order to obtain better distribution behavior the hexanemethanol system of Scholfield and Dutton (33) was modified systematically until a satisfactory combination was found in $n$-butanol-n-heptane-methanol water. The system was prepared by mixing $n$-heptane, $6,000 \mathrm{ml}$; $n$-butanol (saturated with water), $4,000 \mathrm{ml}$; methanol, 1,900 ml.; water, $100 \mathrm{ml}$; and by allowing the system to equilibrate. The inositol lipide was dissolved in the upper phase in 5\% concentration (higher concentrations affect the nature of the distribution (27). The solution was equilibrated with the lower phase, and the mixture was introduced into tube 0 . In the case of the 400-transfer distribution $16 \mathrm{~g}$. of corn inositol lipide were dissolved in $160 \mathrm{ml}$. of the upper phase, and the solution was distributed over the first eight tubes (tubes 0-7) to begin the distribution. At the end of the distribution small aliquots were removed for determination of the weight distribution. Appropriate tubes were combined, and the solvents were removed in vacuo under reduced pressure. The residues were dissolved in benzene, lyophilized, and finally dried in vacuo over phosphorus pentoxide. The distribution results and the elementary and group analyses are summarized in Tables I and II and Figure 1.

\section{Preparation of Crude Phytoglycolipide.}

a) From Corn $I L$. Fifty grams of crude lipide were placed in a 2-liter glass bottle with a ground glass stopper. One liter of $1 \mathrm{~N} \mathrm{KOH}$ was added, the bottle was tightly stoppered, and the mixture was shaken on a mechanical shaking machine in a constant temperature room at $37^{\circ}$ for $24 \mathrm{hrs}$. The yellow soapy solution was poured into a 4-liter beaker, surrounded by an ice bath, and cooled with stirring to $20^{\circ}$. $5 \mathrm{~N} \mathrm{HCl}$ was added slowly with cooling and vigorous stirring to bring the solution to $\mathrm{pH} 1$, and $1,650 \mathrm{ml}$. of acetone were added. The fatty acids dissolved, and a white solid settled fairly rapidly. After centrifugation the supernatant solution was decanted and replaced with $300 \mathrm{ml}$. of a solution consisting of two parts of acetone and one part of $0.5 \mathrm{~N}$ HCl. The precipitate was resuspended by shaking the stoppered centrifuge bottles for $20 \mathrm{~min}$. on a mechanical shaker, the suspension was then centrifuged, and the acetone-acid wash solution was decanted. This washing procedure was repeated three times. 
The final precipitate was suspended in $300 \mathrm{ml}$. of acetone by shaking, and the heavy powder was filtered on a medium fritted glass funnel. The product was dried in vacuo for 24 hrs. (yield $19.0 \mathrm{~g}$.).

b) From Soybean Phosphatide (Acetone-extracted). One hundred grams of crude phosphatide were placed in a 1-gal. glass bottle with ground glass stopper; 2.5 liters of $1 \mathrm{~N} \mathrm{KOH}$ were added, and the bottle was tightly stoppered. The mixture was shaken on a mechanical shaking machine in a constant temperature room at $37^{\circ}$ for $24 \mathrm{hrs}$. Then the bottle was put into an ice bath, and $500 \mathrm{ml}$. of $5 \mathrm{~N} \mathrm{HCl}$ were added slowly with cooling and vigorous shaking. The neutralized mixture was then brought to $\mathrm{pH} 1$ by the addition of $58.5 \mathrm{ml}$. of $98 \%$ formic acid. Stirring was continued until the temperature reached $20^{\circ}$ when $4,740 \mathrm{ml}$. of acetone were added. The fatty acids dissolved, and a white precipitate, which settled fairly easily, was separated by centrifugation. The precipitate thus obtained was again shaken with $500 \mathrm{ml}$. of acetone, containing $2.8 \%$ of formic acid, for $20 \mathrm{~min}$. on a mechanical shaker. The suspension was centrifuged, and the acetone-acid solution was decanted. Next the procedure was repeated, using anhydrous acetone. The final precipitate was suspended in $500 \mathrm{ml}$. of anhydrous acetone by shaking, and the suspension was filtered, giving a white amorphous powder. The product was dried in vacuo for 24 hrs. in a desiccator, which contained both sulphuric acid and sodium hydroxide. The yield in several runs varied between 15 and $18 \mathrm{~g}$.

c) From Other Lipides. Flaxseed IL was prepared according to the method of Carter et al. (1). Commercial peanut lecithin was exhaustively extracted with acetone, and the insoluble material was used as a starting material for the saponification. The same acetone treatment was applied to phosphatides from cottonseed oil, sunflowerseed oil, and wheat germ oil. Individual saponification procedure was essentially identical to that applied to soybean phosphatides.

The phytoglycolipide fractions obtained by this procedure were white amorphous solids with the exception of that from peanut, which was a light brown. Analytical data on these products are recorded in Table IV. The product from corn gave a high phosphorus value as a result of contamination by the lipophytin degradation product. The soybean and peanut products contained a high proportion of sterol glucoside, accounting in part for the low nitrogen and phosphorus values.

Purification of Crude Phytoglycolipides. The solubility properties of phytoglycolipide made purification difficult. Chromatography of pyridine solutions on alumina failed to bring about any significant purification. Attempts to devise pyridine-containing solvent systems which could be used for countereurrent distribution also failed. Extraction with a chloroformethanol mixture $(1: 1$ or $1: 2)$ removed sterol glycosides and some of the impurities but failed to remove the high-phosphorus impurity. However this impurity remained insoluble on pyridine extraction, and the lipide was recovered from the pyridine solution by precipitation with ethanol and purified by washing with acetone and dilute acid to remove pyridine.

a) Crude Product from Corn Inositol Lipide. In the case of the crude phytoglycolipide prepared from corn inositol lipide, the pyridine-ethanol precipitation procedure only was applied. Ten grams of crude phytoglycolipide were placed in a $500-\mathrm{ml}$. centrifuge bottle. Reagent grade pyridine $(100 \mathrm{ml}$.) was added, and the bottle was corked and shaken for $5 \mathrm{~min}$. The suspension was centrifuged, and the supernatant solution was decanted. If the solution was not clear, one teaspoonful of "Hyflo-Super-Cel"' was added, and the suspension was filtered through a medium sintered glass funnel. The clear filtrate was poured into a $500-\mathrm{ml}$. centrifuge bottle, and $200 \mathrm{ml}$. of ethanol were added with stirring. The thick suspension was centrifuged, and the light yellow pyridine-ethanol supernatant solution was decanted. The voluminous precipitate was washed once with pyridine-ethanol (1:2) and once with $300 \mathrm{ml}$. of acetone. The precipitate was suspended in $200 \mathrm{ml}$. of acetone, and $100 \mathrm{ml}$. of $0.5 \mathrm{~N}$ hydrochloric acid were added with stirring. A sticky solid settled rapidly. The suspension was centrifuged, and the acid-acetone was decanted. The sticky precipitate was resuspended in acetone, and the heavy powder thus obtained was filtered onto a medium sintered glass funnel and dried in a vacuum desiccator (yield $7.10 \mathrm{~g}$. of purified phytoglycolipide).

b) Crude Product from Corn Phosphatide. Crude phytoglycolipide (117 g.) was shaken with 4 liters of chloroform saturated with water for $1.5 \mathrm{hrs}$. Then four liters of $95 \%$ ethanol were added to the mixture, which was allowed to stand for $4 \mathrm{hrs}$. at room temperature. The mixture was centrifuged, and the insoluble fraction which gave a negative LiebermanBuchard sterol reaction was separated by decantation. The sterol-free product $(72.0 \mathrm{~g}$.) was then subjected to the pyridine-ethanol procedure described above, giving $29.4 \mathrm{~g}$. of purified phytoglycolipide.

c) From Soybean Phosphatide. A sample of crude phytoglycolipide $(60 \mathrm{~g}$.) was placed in a 2-liter centrifuge bottle, and 1.5 liters of reagent grade pyridine were added. The mixture was thoroughly stirred and immediately centrifuged. The supernatant, which contained most of the sterol glycoside, was separated by decantation. The sticky insoluble material was then transferred to a 1-liter flask with $900 \mathrm{ml}$. of pyridine and left for 72 hrs. The phytoglycolipide gradually dissolved. Then the mixture was again centrifuged, and the pyridine solution was separated by decantation. To this pyridine solution 1.8 liters of $95 \%$ ethanol were added. A cloudy precipitate separated and was allowed to settle over-night in the cold room. The major part of the supernatant was siphoned off, and the remaining solid was further separated by centrifugation. The voluminous precipitate was suspended in $300 \mathrm{ml}$. of acetone and centrifuged. The acetone supernatant was decanted. The precipitate was suspended in $200 \mathrm{ml}$. of acetone, and $100 \mathrm{ml}$. of $0.5 \mathrm{~N} \mathrm{HCl}$ were added with stirring. A sticky solid settled rapidly and was centrifuged. The acid-acetone was decanted, and the sticky precipitate was suspended in acetone. The heavy powder was filtered onto a medium sintered glass funnel and dried in a vacuum desiccator, giving $4.30 \mathrm{~g}$. of purified phytoglycolipide.

The pyridine insoluble fraction $(6.15 \mathrm{~g}$.) was again extracted with 25 volumes of pyridine for a week at room temperature with occasional shaking. The pyridine extract was treated by the procedure described above. The extraction procedure was once more applied to the pyridine insoluble fraction obtained from the second extraction. In this way $4.47 \mathrm{~g}$. of additional purified phytoglycolipide were obtained. 
The low yield of phytoglycolipide in this purification procedure was probably the result of loss in the original pyridine extraction to remove sterol glycoside. It seems likely that use of the chloroform-methanol extraction subsequently developed for removal of sterol glycoside from corn phytoglycolipide would have improved the yield here.

d) From Other Lipides. The purification methods were identical with those applied to corn and soybean lipides.

Table V shows the analytical data and specific rotations of the purified phytoglycolipides.

Purified phytoglycolipide is an amorphous solid, varying in color from light tan to pure white. It is obtained as a fine, nonhygroscopic solid. Phytoglycolipide does not melt, but it browns and chars above $200^{\circ}$. Carefully prepared samples leave no ash when ignited. Phytoglycolipide is soluble in organic bases (pyridine, morpholine). It is insoluble in water and in aqueous acid but dissolves in an aqueous base to give a clear soapy solution, from which the excess base can be removed by dialysis against water or against a buffer of desired $\mathrm{pH}$ (above 3 ). The electrophoretic behavior of these solutions was examined with corn and soybean products. Both phytoglycolipides behaved as a mixture of two acidic materials. The components moved toward the anode even at pH 3. The corn lipide was composed of $65 \%$ of a major component and $35 \%$ of a minor component while the soybean lipide showed a distribution of 95 and $5 \%$.

The infrared spectrum of phytoglyeolipide showed the presence of hydroxyl groups (broad absorption at 3,300-3,400 cm.-1) of an amide group (strong absorption at 1,640 and $1,530 \mathrm{~cm}^{-1}$ ) and of methylene groups $\left(2,820-2,890 \mathrm{~cm}^{-1}\right.$ and $\left.1,470 \mathrm{~cm}^{-1}\right)$. In addition, there was a rather broad medium strength peak at $1,720 \mathrm{~cm} .^{-1}$, indicating the presence of a nonamide carbonyl group (free acid or possibly lactone).

Removal of Lipophytin from Corn Inositol Lipide. A two-phase system was prepared by mixing $n$-hexane, $1,500 \mathrm{ml}$; $n$-butanol saturated with water, 1,000 ml.; methanol, $475 \mathrm{ml}$; water, $25 \mathrm{ml}$. A sample of corn inositol lipide (108 g.) was dissolved in 1,080 $\mathrm{ml}$. of upper phase, and the solution was equilibrated with $1,080 \mathrm{ml}$. of lower phase for $2 \mathrm{hrs}$. The dark brown turbid lower phase was withdrawn and centrifuged for $45 \mathrm{~min}$. (2,500 r.p.m.) at $-5^{\circ}$. The clear brown supernatant was decanted. The light brown residue was dissolved in benzene, and the solution was lyophilized. The residue was dried for $48 \mathrm{hrs}$. over $\mathrm{P}_{2} \mathrm{O}_{5}$ in vacuo, giving $6.24 \mathrm{~g}$. of tan powder (N $0.85 \%, \mathrm{P} 11.97 \%$ ). This material resembles closely the heptane-soluble fraction (E) obtained in the 400 transfer countercurrent distribution.

The upper and lower phases were combined and evaporated to dryness under reduced pressure. The residue was dissolved in benzene and lyophilized, giving $95.5 \mathrm{~g}$. of purified corn IL (N $0.77 \%, \mathrm{P} 3.73 \%$, LCB $\mathrm{N} 0.31 \%$ ).

\section{Composition of Phytoglycolipide.}

a) Detection of Sugars. A $20-\mathrm{mg}$. sample of phytoglycolipide was hydrolyzed with $0.5 \mathrm{ml}$. of $0.5 \mathrm{~N}$ $\mathrm{H}_{2} \mathrm{SO}_{4}$ at $100^{\circ}$ for 12 hrs. The aqueous solution was filtered and neutralized with Dowex $2\left(\mathrm{HCO}_{3}{ }^{-}\right.$phase). The resulting solution was subjected to descending chromatography in two solvent systems and compared with a standard mixture of arabinose (A), galactose (G), and mannose (M). The spots were developed with aniline phthalate. The fastest-moving spot was assigned an "Rx" value of 1.00 and the others were compared with it. The results are summarized below.

\begin{tabular}{l|ll|ll}
\hline \multicolumn{1}{c|}{ Solvent System } & \multicolumn{2}{|c|}{ "Rx" of Hydrolysate } & \multicolumn{2}{|c}{ "Rx" of Standards } \\
\hline Lutidine-Water & pink & 1.00 & $\operatorname{pink}(\mathrm{A})$ & 1.02 \\
$13: 7$ & brown & 0.95 & $\operatorname{brown}(\mathrm{M})$ & 0.96 \\
& red-brown & 0.84 & red-brown(G) & 0.84 \\
n-Butanol-acetic & pink & 1.00 & pink(A) & 1.00 \\
acid-water & brown & 0.96 & brown(M) & 0.95 \\
$(4: 1: 1)$ & brown & 0.88 & brown(G) & 0.86 \\
\hline
\end{tabular}

Two-dimensional chromatography, using these two systems, also showed identical behavior of the hydrolysate and the standard solution.

b) Isolation of Mannose Phenylhydrazone. A sample of phytoglycolipide $(6.2 \mathrm{~g}$.) was refluxed with $100 \mathrm{ml}$. of $0.3 \mathrm{~N}$ methanolic $\mathrm{HCl}$ for $3 \mathrm{hrs}$. The solution was cooled to $0^{\circ}$ and filtered. The filtrate was concentrated under reduced pressure. The residue was dissolved in $50 \mathrm{ml}$. of $0.5 \mathrm{~N} \mathrm{H}_{2} \mathrm{SO}_{4}$, and the solution was refluxed for 12 hrs., cooled, and filtered. The solution was neutralized with Dowex $2\left(\mathrm{HCO}_{3}-\right.$ phase) to $\mathrm{pH} 6$. The filtrate was concentrated to a syrup $(0.46 \mathrm{~g}$.) on the water pump; $150 \mathrm{mg}$. of the syrup were dissolved in $4 \mathrm{ml}$. of water, and two drops of phenylhydrazine were added. The solution was allowed to stand $1 \mathrm{hr}$. at room temperature. The heavy precipitate was filtered and recrystallized from methanol, giving $15 \mathrm{mg}$. of phenylhydrazone melting at $182-184^{\circ}$ (hot stage, uncorr.).

$$
\begin{array}{ll}
\mathrm{C}_{12} \mathrm{H}_{18} \mathrm{O}_{5} \mathrm{~N}_{2} . & \text { Calculated: } \\
\text { Found: } & \text { C 53.31, } \mathrm{H} 6.71, \mathrm{~N} 10.83, \mathrm{H} 6.48, \mathrm{~N} 11.01
\end{array}
$$

The infrared spectrum of this material was identical with that of authentic. mannose phenylhydrazone (m.p. 186-188 ${ }^{\circ}$ ).

c) Inositol. Inositol was liberated from phytoglycolipide by hydrolysis with $6 \mathrm{~N} \mathrm{HCl}$ at $100^{\circ}$ for $6 \mathrm{hrs}$. It was visualized on paper with the silver nitratesodium hydroxide or the periodate-permanganate reagent. In 2-propanol-acetic acid-water (3:1:1), inositol $\left(R_{\mathrm{f}} \quad 0.14-0.20\right)$ was cleanly separated from glucosamine.

Pure inositol was obtained in the course of the glucosamine isolation procedure. The effluent from the IR 120 column before elution with acid was lyophilized. The dry residue ( $0.26 \mathrm{~g}$.) was dissolved in $3 \mathrm{ml}$. of water, and ethanol was added to make $30 \mathrm{ml}$. The mixture was stored at $2^{\circ}$. White crystals formed slowly. The solution was stored at $-10^{\circ}$ for 2 days. The white solid was collected, washed with ethanol, and dried. This crop of crystals weighed $44 \mathrm{mg}$. (from $1.5 \mathrm{~g}$. of lipide) and melted at 218 $223^{\circ}$. The infrared spectrum of this material was identical with that of authentic inositol. In three solvent systems it showed an $R_{f}$ on paper identical with that of authentic inositol. After one recrystallization from ethanol-water the material melted at $227-230^{\circ}$. Authentic inositol melted at 227-228 $8^{\circ}$ on the same stage.

d) Inositol Phosphate. One gram of corn phytoglycolipide was hydrolyzed with $20 \mathrm{ml}$. of $6 \mathrm{~N} \mathrm{HCl}$ under reflux for $1 \mathrm{hr}$. The hydrolysate was placed in the cold room for $3 \mathrm{hrs}$, and the floating solid was removed. The filtrate was lyophilized, and the residue was dissolved in $10 \mathrm{ml}$. of water. The solution was 
clarified with Super-Cel to remove humin-like material. An excess of lead acetate solution was added to the filtrate. The precipitate which formed immediately was separated by centrifugation and washed with water several times. The residue was suspended in $10 \mathrm{ml}$. of water and treated with $\mathrm{H}_{2} \mathrm{~S}$. The lead sulphide formed was removed by filtration, and the colorless filtrate was concentrated in vacuo to $0.3 \mathrm{ml}$. Absolute ethanol (25 ml.) was added, and the turbid solution was left in the cold room over-night. The white powdery precipitate was separated by decantation, washed with ether, and dried (yield $10.7 \mathrm{mg}$.). This material behaved exactly like authentic inositol monophosphate on paper chromatography $\left[\begin{array}{ll}\mathbf{R}_{f} & 0.4\end{array}\right.$ with 2-propanol:conc. $\mathrm{NH}_{4} \mathrm{OH}$ : water $(5: 4: 1)$ (9) visualized with the Hanes-Isherwood and with the periodate permanganate reagents] and gave an identical infrared spectrum. In another hydrolysis $100 \mathrm{mg}$. of inositol monophosphate were obtained. The crude product was twice reprecipitated as described above. The purified product decomposed at 200-210 .

e) Ninhydrin Positive Materials. Paper Chromatography. Phytoglycolipide samples were hydrolyzed with $3 \mathrm{~N}$ sulfuric acid at $170^{\circ}$ for 4 hrs., or preferably with $6 \mathrm{~N}$ hydrochloric acid at $100^{\circ}$ for $6 \mathrm{hrs}$. for the detection of ninhydrin-positive materials.

The solvent system 2-propanol-acetic acid-water ( $3: 1: 1)$ was found to be most effective for separating the ninhydrin-positive components of phytoglycolipide. Two other systems were used for the tentative identification of ethanolamine.

$R_{f}$ of Materials in Varions Solvent Systems

\begin{tabular}{|c|c|c|c|}
\hline & $\begin{array}{c}\text { 2-Propanol-acetic } \\
\text { acid-water } \\
3: 1: 1\end{array}$ & $\begin{array}{c}\text { n-Butanol-acetic } \\
\text { acid-water } \\
\mathbf{4}: 1: 1\end{array}$ & $\begin{array}{l}n \text {-Propanol-acetic } \\
\text { acid-water } \\
(10: 1: 9)\end{array}$ \\
\hline $\begin{array}{l}\text { Ethanolamine } \\
\text { Serine }\end{array}$ & $\begin{array}{l}0.62 \text { red-violet } \\
0.34 \text { violet }\end{array}$ & 0.57 red-violet & $\begin{array}{l}0.61 \text { red-violet } \\
0.41 \text { violet }\end{array}$ \\
\hline $\begin{array}{l}\text { Phosphoryl } \\
\text { ethanolamine }\end{array}$ & $\begin{array}{l}0.22 \text { violet } \\
0.65 \text { red-vio }\end{array}$ & & 0.35 violet \\
\hline Hydrolysate & $\left|\begin{array}{l}0.60 \text { red-violet } \\
0.46 \text { violet } \\
0.32 \text { gray violet } \\
0.26 \text { intense } \\
\quad \text { black-violet }\end{array}\right|$ & $\begin{array}{l}0.56 \text { red-violet } \\
\text { long streak of } \\
\text { lower } R_{f} \text {. }\end{array}$ & $\begin{array}{l}0.63 \text { red-violet } \\
0.40 \text { light violet } \\
0.23 \text { black-violet }\end{array}$ \\
\hline
\end{tabular}

D-Glucosamine. The first isolation was accomplished by chromatography on IR 120, hydrogen phase, followed by chromatography on a wide strip of Whatman No. 1 filter paper and elution of the band of proper $R_{\mathrm{f}}$. This gave $3 \mathrm{mg}$. of a white solid. The infrared specrum suggested an amino sugar, and comparison with the spectrum of glucosamine hydrochloride revealed a remarkable similarity.

A large-scale isolation was then undertaken. A sample of purified phytoglycolipide (1.5 g.) was refluxed with $150 \mathrm{ml}$. of $6 \mathrm{~N}$ hydrochloric acid for 6 hrs. The hydrolysate was cooled and filtered. The filtrate was reduced to dryness in a vacuum desiccator. The residue was dissolved in $5 \mathrm{ml}$. of water and neutralized to $\mathrm{pH} 4$ by addition of Dowex 2 , $\left(\mathrm{HCO}_{3}\right.$ phase). The resin was filtered, and the filtrate was passed onto a column consisting of $30 \mathrm{ml}$. of IR 120 , ( $\mathrm{H}^{+}$phase), packed into a $50-\mathrm{ml}$. burette. The resin was washed with water, and the neutral fraction was collected. (This material was used in the isolation of inositol.) The resin was eluted with $0.3 \mathrm{~N} \mathrm{HCl}$. The ninhydrin-positive fraction was eluted between 50 $\mathrm{ml}$. and $150 \mathrm{ml}$. of acid. This fraction was reduced to small volume, neutralized with Dowex 2, $\mathrm{HCO}_{3}$ phase), and lyophilized. The residue weighed $0.141 \mathrm{~g}$.

A portion of this crude base fraction ( $0.12 \mathrm{~g}$.) was dissolved in $0.5 \mathrm{ml}$. of water, 2 drops of concentrated hydrochloric acid were added, and absolute ethanol was added to make a total volume of $25 \mathrm{ml}$. This solution was cooled, and then $3 \mathrm{ml}$. of acetone were added. The mixture was permitted to stand at $-10^{\circ}$ over-night, giving a crop of fine white crystals.

After two recrystallizations the total crude base fraction yielded $58.5 \mathrm{mg}$. of pure D-glucosamine hydrochloride.

\section{$\mathrm{C}_{6} \mathrm{H}_{14} \mathrm{O}_{5} \mathrm{NCl}$. Calculated: C 33.40, H 6.58, N 6.48 Found: $\quad$ C 33.71, H 6.57, N 6.49}

On paper this material gave a double spot identical with that of authentic D-glucosamine hydrochloride (21), as visualized with silver nitrate, periodate, or Elson-Morgan sprays. The infrared spectrum and X-ray diffraction pattern were identical to those of D-glucosamine hydrochloride. The optical rotation and mutarotation were observed.

\begin{tabular}{c|c}
\hline$[a]=\frac{25}{D}$ (in water) & Time \\
\hline degrees & hours \\
+96.2 & 1 \\
+78.3 & 2 \\
+70.0 & 4 \\
+68.8 & 24
\end{tabular}

f) Phytosphingosine. Corn and soybean phytoglycolipides were hydrolyzed with methanolic $\mathrm{H}_{2} \mathrm{SO}_{4}$, and the acetone compound and N-benzoyl derivative of the free base were prepared as previously described (1). Corn phytoglycolipide gave characteristic phytosphingosine derivatives, but the soybean products differed in melting point as summarized below.

\begin{tabular}{|c|c|c|}
\hline Compound & M.p. (Corn) & M.p.(Soybean) \\
\hline Free base... & $101.5-103^{\circ}$ & $91.5-93^{\circ}$ \\
\hline Acetone derivative........................... & $105-107^{\circ}$ & $114-117^{\circ}$ \\
\hline $\mathrm{N}$-benzoyl derivative......................... & $136-137^{\circ}$ & $125-127^{\circ}$ \\
\hline
\end{tabular}

Furthermore the soybean products showed a sharp trans double bond peak in the infrared at $970 \mathrm{~cm}^{-1}$. The absence of the anhydro base or $\mathrm{O}$-methyl ether: was indicated by the lack of infrared peaks in the region $1,110-1,150 \mathrm{~cm}^{-1}$.

Microhydrogenation [apparatus similar to that of Frampton et al. (14)] gave an uptake of 0.65 moles of hydrogen per mole of N-benzoyl derivative. The reduced product gave no peak at $970 \mathrm{~cm}^{-1}$ and melted at $135^{\circ}$. It seems probable that the soybean N-benzoyl derivative is a mixture of N-benzoyl-phytosphingosine and an unsaturated derivative of phytosphingosine. The structure of this material is being investigated further.

f) Fatty Acids. A sample of crude corn phytoglycolipide $(1.20 \mathrm{~g}$.) was hydrolyzed with $6 \mathrm{~N}$ hydrochloric acid for $6 \mathrm{hrs}$. at $100^{\circ}$. The hydrolysate was filtered, and the black residue was washed thoroughly with water. The residue was washed with a few mi. of acetone and then dissolved in $200 \mathrm{ml}$. of a chloroform-methanol mixture $(4: 1)$. The acetone wash was added to the chloroform-methanol solution, $1 \mathrm{~g}$. of Dareo was added, and the mixture was warmed to boiling. The hot solution was filtered through a pad 
of "Hyflo-Super-Cel." The brown filtrate was taken to dryness. 'The dark residue weighed $0.53 \mathrm{~g}$.

A slurry of silicic acid (Mallinkrodt No. 2847, acid-and acetone-washed) was prepared in reagent grade chloroform (contains $0.75 \%$ ethanol). This slurry was poured into a 2.5 by $40-\mathrm{cm}$. column fitted with a stopcock at the bottom and containing a glass wool plug. The slurry was allowed to settle to give a column of adsorbent 2.5 by $26.5 \mathrm{~cm}$. The sample was applied in $10 \mathrm{ml}$. of warm chloroform. The column was eluted with reagent grade chloroform. No pressure was applied other than a $20-\mathrm{cm}$. head of chloroform. Fractions of about $10 \mathrm{ml}$. each were collected with a time-controlled fraction collector. The flow rate varied somewhat and had to be controlled by means of the stopcock in order to collect fractions of uniform volume. The fractions were evaporated to dryness in tared test tubes, and the residues were weighed after thorough drying.

The total weight of material eluted was $207 \mathrm{mg}$. (17.3\% of the weight of original lipide). Three peak fractions (I, II, III) were obtained (I and II not cleanly separated).

Fraction I (tubes 6-10; weight $50.2 \mathrm{mg}$.) melted at $39-49^{\circ}$, and the neutralization equivalent and infrared spectrum indicated a mixture of palmitic and stearic acids.

Fraction II (tubes 11-21; weight $22.5 \mathrm{mg}$.) melted at $75-77.5^{\circ}$. On recrystallization from ethyl acetate the melting point sharpened to $76-77.5^{\circ}$. This material gave analytical data in good agreement with those of lignoceric acid (m.p. $84^{\circ}$ ) although the melting point is somewhat low.

$$
\begin{array}{ll}
\mathrm{C}_{24} \mathrm{H}_{48} \mathrm{O}_{2} \text {. Calculated: } & \text { C 78.19, H } 13.3 \\
\text { Found: } & \text { C 78.30, H } 13.33
\end{array}
$$

Fraction III (tubes 28-40; weight $127 \mathrm{mg}$. ) was recrystallized from $2 \mathrm{ml}$. of ethyl acetate giving 103 mg. of a white solid melting at 100-102 ${ }^{\circ}$. After a second recrystallization the acid melted at $103-104^{\circ}$. The infrared spectrum of this material was identical with that of authentic cerebronic acid. However the analytical data were not in good agreement.

$$
\begin{array}{lll}
\mathrm{C}_{24} \mathrm{H}_{48} \mathrm{O}_{3} . & \text { Calculated: } & \mathrm{C} 74.93, \mathrm{H} 12.58 \\
\mathrm{C}_{26} \mathrm{H}_{50} \mathrm{O}_{3} \text {. Calculated: } & \text { C 75.72, H 12.61 } \\
& \text { Found: } & \text { C 75.30, H 12.41 }
\end{array}
$$$$
\text { Found (soybean) : C 74.39, H } 12.20
$$

Furthermore pure cerebronic acid melts at 100 $101^{\circ}$. Chibnall et $a l$. (6) reported that yeast cerebrin gave, on hydrolysis, a 90:10 mixture of a-hydroxyhexacosanoic acid and cerebronic acid. This mixture melted at $103.5-103.7^{\circ}$. Proštenik (28) has also isolated an $a$-hydroxy acid from yeast cerebrin, melting at $101-103^{\circ}$, to which he assigned the $\mathrm{C}_{26}$ structure. On the basis of melting point behavior and analytical data it seems almost certain that the material from corn phytoglycolipide is a mixture of cerebronic and $a$-hydroxyhexacosanoic acid while a similar sample from soybean gave analytical data corresponding more closely to those for cerebronic acid.

\section{Summary}

A new complex lipide, phytoglycolipide, has been isolated from soybean, corn, flaxseed, peanut, sunflowerseed, cottonseed, and wheat phosphatides. This material is obtained by a mild alkaline saponification procedure which destroys glycerol-containing lipides. The new lipide constitutes about $5 \%$ of the crude phosphatides and is obtained as a white amorphous powder of identical composition, optical activity, and solubility properties from the various sources. Phytoglycolipide gives on hydrolysis phytosphingosine (and, in the case of soybean only, an unsaturated derivative of phytosphingosine) fatty acids, inositol, glucosamine, a hexuronic acid, galactose, arabinose, mannose, and phosphate.

Phytoglycolipide is the first sphingolipide of plant origin to be described and is unique among complex sphingolipides in that it has the structural features of a glycolipide and of a phosphatide.

\section{Acknowledgment}

The authors are happy to acknowledge generous gifts of soybean phosphatides from the A. E. Staley Manufacturing Company, the Glidden Company, and the American Irecithin Company Inc.; of corn phosphatides from Refining Unincorporated; of flaxseed phosphatide from the Minnesota Linseed Oil Company; of cottonseed phosphatides from I. A. Goldblatt, Southern Utilization Research and Development Division, Agricultural Research Service; of sunflowerseed phosphatide from Co-Op Vegetable Oils Ltd.; and of wheat germ oil from the VioBin Corporation.

The authors wish to express their appreciation to Mrs. Ancilla Bay and Mrs. Harriett Crum for extensive technical assistance during the course of these studies.

\section{REFERENCES}

1. Oarter, H. E., Celmer, W. D., Lands, W. E. M., Mueller, K. L., and Tomizawa, H. H., J. Biol, Chem., 206, 613 (1954)

2. Carter, H. E., and Fujino, Y., J. Biol. Chem., 22x, 879 (1956). 3. Carter, H. E., Galinos, D. S., and Fujino, Y., Canad. J. Biochem. and Physiol., 34, 320 (1956).

4. Oarter, H. E., Galanos, D. S., Gigg, R. H., Law, J. L., Naka yama, T., Smith, D, B., and Weber, E. J., Federation Proc., 16, 817

5. Celmer, W. D., and Carter, H. E., Physiol. Rev., 32, 167 (1952). 6. Chibnall, A. C., Piper, S. H., and Williams, E, F., Biochem. J., $55,711(1953)$

7. Graig, L. O., J. Biol. Chem., 155, 519 (1944)

8. Davidson, E. A., and Meyer, K., J. Am. Ohem. Soc., 76, 5686 $1954)$.

9. Desjobert, A., and Petek, F., Bull, soc. chim. biol., 38, 871 (1956). 10. Dische, Z., J. Biol. Chem., 167, 189 (1947).

11. Faure,

12 Folch. T Federation Proc 6, 252 (1947).

13. Folch, J, "Phosphorus Metabolism," vol. 2, p. 186, Baltimore. Williams and Wilkins, 1952.

14. Frampton, V. L., Edwards, J. D. Jr., and Herze, H. R., J. Am. Chem. Soc., 73, 4,432 (1951).

15. Harris, W. D., and Pranjivar, P., J. Am. Oil Chemists' Soc.,

16. Hawthorne, J. N., Intern. Colloquium Biochem. Problem, Lipiden, p. 59, Koninkl. Vlaam. Acad. Wetenschap., letter, en Schone Kunsten België, Kl. Wetenschap., 1953.

17. Hawthorne, J. N., Biochim. et Biophys., Acta, 18, 389 (1955) 18. Hawthorne, J. N., and Chargaff, E., J. Biol. Chem., 206, 27

19. Hutt, H. W., Malkin, 'T., Poole, A. G., and Watt, P. R., Nature, $165,314(1950)$

20, KIenk, E., and Sakai, R., Z. physiol. Chem., 258, 33 (1939). 21. Leaback, D. H., and Walker, P. G., Biochem. J., 67, $22 \mathrm{P}$ (1957).

22. MeGuire, T. A., and Earle, F. R., J. Am. Oil Chemists' Soc. 23. McKibben, J. M., and Taylor, W. E., J. Biol. Chem., 178, 291 (1.949)

24. Malkin, T., and Poole, A. G., Chem. Soc., 3,470 (1953)

25. Okuhara, E., and Nakayama, T., J. Biol. Chem., 215, 295 $(1955)$.

26. Olcott, H. S., Science, 100, 226 (1944).

27. Olley, J., Biochim. et Biophys. Acta, 10, 493 (1953)

28. Prostenik, M., Croat. Chem. Acta, 28, 287 (1956).

29 . Prostenik, M., and Stanacev, N. Z., Naturwissenschaften, 43 447 (1956).

$217,789(1955)$.

31. Schmidt, G., Benotti, J., Hershman, B., and Thannhauser, S. J., J. Biol. Ohem., 166, 505 (1946)

32. Scholfield, O. R., and Dutton, H. J., J. Biol. Chem., 208, 461 (1954).

33. Scholfield, O. R., Dutton, H. J., and Dimler, J., J. Am. Oil

Chemists' Soc., 29, 293 "(1952). Amsterdam, D. B. Centen. 1954; Rec. trav. chim.. 72, 764 (1953). 35. Wagenknecht, A. C., and Carter, H. E., Federation Proc., 16 266 (1957).

36. Weissmann, B., Rapport, M, M., Tinker, A., and Meyer, K., J. Biol. Chem., 205, 205 (1953)

37. Woolley, D. W., J. Biol. Chem., 147, 581 (1943).

[Received December 16, 1957] 